\title{
Exploiting genetic polymorphisms in metabolic enzymes for rapid screening of Leishmania infantum genotypes
}

\author{
Marcello Ceccarelli ${ }^{1}$, Aurora Diotallevi ${ }^{1}$, Francesca Andreoni ${ }^{1}$, Fabrizio Vitale ${ }^{2}$, Luca Galluzzi ${ }^{{ }^{* \dagger}}$ (D) \\ and Mauro Magnani ${ }^{1+}$
}

\begin{abstract}
Background: Leishmania infantum is the aetiological agent of visceral leishmaniasis (VL) and cutaneous leishmaniasis (CL). Numerous strains and/or zymodemes have been identified and characterized by multilocus enzyme electrophoresis (MLEE). MLEE is considered the reference method for L. infantum parasite typing and it is based upon enzyme electrophoretic mobility analysis from promastigote cultures. However, the MLEE technique is cumbersome, timeconsuming and does not detect silent genetic mutations or nucleotide changes that give rise to amino acid changes that do not alter electrophoretic mobility. As a result of these difficulties, many DNA-based typing methods have been developed over the past few years. However, relative to the enzymes utilized in MLEE analysis, we observed a shortage of DNA sequences available in the GenBank database or an absolute lack of sequences belonging to specific zymodemes. The aims of the present study were to (i) implement the number of sequences coding for metabolic enzymes used in MLEE; (ii) identify polymorphisms that characterize L. infantum zymodemes most prevalent in the Mediterranean basin; and (iii) exploit these polymorphisms to develop a rapid screening test that would give results comparable with existing MLEE typing.

Results: Partial sequences of seven metabolic enzyme genes (malic enzyme, 6-phosphogluconate dehydrogenase, mitochondrial isocitrate dehydrogenase, glucose-6-phosphate isomerase, glucose-6-phosphate dehydrogenase, phosphoglucomutase and mannose phosphate isomerase) were obtained from $11 \mathrm{~L}$. infantum strains. The comparison of these sequences with those obtained from GenBank allowed for the identification of a few polymorphisms that could distinguish several zymodemes. In particular, the polymorphism 390T>G in the malic enzyme gene has been exploited to develop a high-resolution melt (HRM)-based assay to rapidly differentiate the genotype 390T, associated with zymodemes MON-1, MON-72 and MON-201, evidencing a partial agreement between genotyping results and MLEE. The assay has been successfully applied to L. infantum clinical isolates and clinical samples.
\end{abstract}

Conclusions: A HRM-based assay for rapid identification of genotypes associated with the most common L. infantum zymodemes in the Mediterranean basin has been developed and its potential application in epidemiological research for L. infantum population screening, without parasite isolation and culturing, has been demonstrated.

Keywords: Leishmania infantum, Isoenzymes, Zymodeme, MON, HRM, Malic enzyme, SNP

\footnotetext{
* Correspondence: luca.galluzzi@uniurb.it

'Luca Galluzzi and Mauro Magnani contributed equally to this work.

'Department of Biomolecular Sciences, University of Urbino "Carlo Bo",

Urbino, PU, Italy

Full list of author information is available at the end of the article
}

(C) The Author(s). 2018 Open Access This article is distributed under the terms of the Creative Commons Attribution 4.0 International License (http://creativecommons.org/licenses/by/4.0/), which permits unrestricted use, distribution, and reproduction in any medium, provided you give appropriate credit to the original author(s) and the source, provide a link to the Creative Commons license, and indicate if changes were made. The Creative Commons Public Domain Dedication waiver (http://creativecommons.org/publicdomain/zero/1.0/) applies to the data made available in this article, unless otherwise stated. 


\section{Background}

The taxonomy of the genus Leishmania is complex and has been revised several times in light of parasite biology and biochemistry $[1,2]$. Currently, the genus Leishmania includes four subgenera: Leishmania, Viannia, Sauroleishmania and L. enriettii complex. Each subgenus includes several species [1]. Leishmania infantum, the aetiological agent of visceral leishmaniasis (VL) and cutaneous leishmaniasis (CL), belongs to subgenus Leishmania [3].

Multilocus enzyme electrophoresis (MLEE) is the isoenzymatic analysis presently considered the reference method for parasite typing by the World Health Organization [4]. This technique, developed at the Centre for Leishmaniasis of Montpellier (France), is based on the electrophoretic mobility of several enzymes obtained from promastigote culture, as described by Rioux et al. [5]. Up to 15 enzymes can be considered in this analysis: malate dehydrogenase, malic enzyme, isocitrate dehydrogenase (NADP), phosphogluconate dehydrogenase, glucose-6-phosphate dehydrogenase, glutamate dehydrogenase, cytochrome-b5 reductase, purinenucleoside phosphorylase 1 and 2, glutamic-oxaloacetic transaminase 1 and 2, phosphoglucomutase, fumarase, mannose-6-phosphate isomerase, and glucose-6-phosphate isomerase [6]. The comparison of isoenzyme mobility with a reference strain identified over 300 zymodemes, also termed MON.

Concerning L. infantum, 45 zymodemes have been found, 36 recognized as real zymodemes and 9 as variants [6]. In dogs in the Mediterranean area, 12 zymodemes have been found: MON-1, MON-24, MON-34, MON-72, MON-77, MON-80, MON-98, MON-105, MON-108, MON-199, MON-199 variant NP1130 and MON-281. With the exception of MON-105, these zymodemes have also all been found in humans [6]. Other zymodemes, such as MON-11, MON-27, MON28, MON-29 MON-33 and MON-189, have been isolated only from humans [7]. Leishmania infantum MON-1 is the most frequent zymodeme in both humans and dogs in the Mediterranean basin [8] and in the New World [9]. It is present in 30 countries and represents about $70 \%$ of all identified strains. In particular, MON-1 represents $88 \%$ of $L$. infantum zymodemes in the south of France [10], $96.7 \%$ in Portugal [11] and $45-58 \%$ in Spain [12, 13]. Moreover, in HIV-infected subjects, MON-1 was found in about $73 \%$ of co-infections, while in immunocompetent patients it was found in about $90 \%$ of VL cases and 20\% of CL cases [14]. Concerning canine infections in Italy, Gramiccia et al. [15] showed a high prevalence of MON-1 zymodeme (91\%) in $497 \mathrm{ca}-$ nine clinical isolates, with the remaining percentage composed almost exclusively of MON-72 zymodeme. The homogeneity of the isoenzymes identified in the dog population does not fully reflect the isoenzyme diversity in humans; therefore, the role of canine population as the only reservoir for all $L$. infantum zymodemes remains unclear. In light of this epidemiological evidence, it is advisable that a more extensive typing of $L$. infantum be carried out. However, MLEE presents several disadvantages: it is time-consuming, technically demanding, and requires bulk cultures of parasites. Moreover, due to its inability to detect nucleotide substitutions that do not change the amino acid composition, its discriminatory power is poor. Therefore, molecular approaches such as multilocus microsatellite typing (MLMT) [16, 17] and multilocus sequence typing (MLST) [18-20] have been introduced for strain discrimination. MLST results were generally in agreement with MLEE, though increased resolution was obtained and some key discrepancies were found [18-21]. For example, $L$. infantum zymodeme MON-1 has been shown to be genetically heterogeneous. On the other hand, it was also shown that strains classified as different zymodemes can present the same genotype [18, 20]. However, the low number of typed strains and the lack of consensus on the marker genes, as well as the lack of MLST database for Leishmania, have hindered the implementation of MLST as a reference typing method [22]. Until now, most of the epidemiological data available in the literature is based on MLEE classification, and many DNA-based typing methods correlate data with existing MLEE classification [23, 24].

In this study, we explored the sequences of seven $L$. infantum genes encoding enzymes considered in MLEE analysis with the aim of (i) enriching the actual databases; (ii) identifying polymorphisms that characterize $L$. infantum zymodemes most prevalent in the Mediterranean basin; and (iii) developing a rapid screening test that would give results that could be associated with existing MLEE data, overcoming the drawbacks of this laborious technique.

\section{Methods \\ Leishmania infantum DNA}

Leishmania infantum strains or isolates used in this study are listed in Table 1. The Chelex-purified DNA from promastigotes of L. infantum strains or isolates was obtained from the National Reference Center for Leishmaniasis (C.Re.Na.L.), Istituto Zooprofilattico Sperimentale della Sicilia (Palermo, Italy). The DNA was quantified using a Qubit fluorometer (Life Technologies, Carlsbad, USA).

\section{Identification of molecular targets and PCR amplification}

A preliminary in silico analysis was performed in the GenBank sequence database to search for genes encoding enzymes used in MLEE for L. infantum. These genes were selected not only to gain information on genetic diversity, but also to connect the genotyping results to the 
Table 1 Leishmania infantum strains/isolates used in this study

\begin{tabular}{lll}
\hline Species & Strain or clinical isolate & Zymodeme \\
\hline L. infantum & MHOM/TN/80/IPT1 & MON-1 \\
L. infantum & MHOM/FR/78/LEM75 & MON-1 \\
L. infantum & Clinical isolate V2921 & MON-1 \\
L. infantum & Clinical isolate 31U & MON-1 \\
L. infantum & Clinical isolate 49U & MON-1 \\
L. infantum & Clinical isolate 10816 & MON-1 \\
L. infantum & Clinical isolate 791 & MON-1 \\
L. infantum & MHOM/DZ/82/LIPA59 & MON-24 \\
L. infantum & MHOM/ES/81/BCN1 & MON-29 \\
L. infantum & MHOM/IT/86/ISS218 & MON-72 \\
L. infantum & MHOM/IT/93/ISS822 & MON-201 \\
L. infantum & Isolate 1 & Not determined \\
L. infantum & Isolate 2 & Not determined \\
\hline
\end{tabular}

existing MLEE data. Six genes were initially selected, based on previous studies performed on L. infantum that allowed the retrieval of available polymorphic sequences from GenBank, i.e. malic enzyme (me), 6-phosphogluconate dehydrogenase $(p g d)$, mitochondrial isocitrate dehydrogenase $(i c d)$, glucose-6-phosphate isomerase (gpi), glucose-6-phosphate dehydrogenase $(g 6 p d h)$ and mannose phosphate isomerase (mpi). Moreover, the phosphoglucomutase (pgm) gene was also taken into consideration in an attempt to enrich the existing database. Primers were designed with PrimerBLAST [25] using $L$. infantum MHOM/FR/78/LEM75 or MCAN/AR/10/MDP1 sequences as reference. The primers are listed in Table 2 and their position on the seven target genes are shown in Additional file 1: Figure S1.

Conventional PCR was performed on a total volume of 50 $\mu \mathrm{l}$ with $1-2 \mu \mathrm{l}$ of template, $200 \mu \mathrm{M}$ dNTP, $2.5 \mathrm{mM} \mathrm{MgCl}$, $200 \mathrm{nM}$ of each primer and 1 unit of Hot-Rescue DNA polymerase (Diatheva s.r.l., Fano, Italy). The amplification was performed in a PCR GeneAmp 2700 thermocycler
(Applied Biosystems, Foster City, USA). The thermal cycling profile was as follows: $94{ }^{\circ} \mathrm{C}$ for $7 \mathrm{~min}$; followed by 35 cycles at $94{ }^{\circ} \mathrm{C}$ for $30 \mathrm{~s}, 60{ }^{\circ} \mathrm{C}$ for $20 \mathrm{~s}$ or $60 \mathrm{~s}$ (depending on amplicon length) and $72{ }^{\circ} \mathrm{C}$ for $20 \mathrm{~s}$; with a final extension at $72{ }^{\circ} \mathrm{C}$ for $5 \mathrm{~min}$. Each sample was amplified in duplicate. Amplified fragments were analyzed by agarose gel electrophoresis and visualized with GelRed DNA stain (Biotium, Fremont, USA). The gels were visualized under UV light using a gel doc apparatus (Bio-Rad, Hercules, USA). A 100-bp double-stranded DNA ladder or ФX174 DNA/BSU/ HaeIII/marker 9 (MBI Fermentas, Waltham, USA) was included on the gels as a size standard.

\section{PCR product sequencing and phylogenetic analysis}

The amplification products of $m e, p g d, i c d, g p i, g 6 p d h, m p i$ and pgm genes for all the strains/isolates are indicated in Table 1 (with the exception of isolate 1 and isolate 2) were purified using a Minelute PCR purification kit (Qiagen, Hilden, Germany) and directly sequenced. DNA sequencing was performed using the BigDye Terminator v. 1.1 Cycle Sequencing Kit on an ABI PRISM 310 Genetic Analyzer (Applied Biosystems). Bases with Phred values $<20$ were checked by visual analysis of electropherograms and aligned with BioEdit Sequence Alignment Editor [26] using default options. Heterozygosity was considered to be present when direct sequencing of PCR product yielded a similar peak at the same site. The sequences were deposited in GenBank with the following accession numbers: MF375413-MF375423 (me), MF280205-MF280215 (pgd), MF347625-MF347635 (icd), MF288905-MF288915 (gpi), MF479731-MF479741 ( $g 6 p d h)$, MF462101-MF462111 (mpi) and MF347614-MF347624 (pgm).

For each housekeeping gene, allele numbers were assigned to unique sequences and a genotype was determined as the combination of the six genes selected for analysis (Additional file 2: Table S1). In total, 54 isolates/ strains belonging to 22 different $\mathrm{MON}$, were analyzed; 23 of them had sequences available for $m e, p g d$, icd, gpi,

Table 2 Primers used in this study

\begin{tabular}{lllll}
\hline Target gene & GenBank ID & Forward primer (5'-3') & Reverse primer (5'-3') & Amplicon length (bp) \\
\hline Malic enzyme $^{a}$ & DQ449701.1 & GAGCCGATCAACCGCTATCA & TCTTCTTCATCCCGGCTC & 773 \\
Malic enzyme $^{b}$ & DQ449701.1 & GGTGTGGCGGAGAGCATC & TTGTTGCCTTGGATGGTTG & 458 \\
Malic enzyme $^{c}$ & DQ449701.1 & TCAGAACCTTCGCAAGACGA & CACTTGCCGATGCTGATGC & 111 \\
Phosphogluconate dehydrogenase & AM157139.1 & TTCGGCTTCGACAACGATCA & CGAGGGAATTGGGGATG & 306 \\
Mitochondrial isocitrate dehydrogenase & DQ449672.1 & CTCCAGCACCAACGTCTACC & TACATGCGCTGGAAGGTCTG & 708 \\
Glucose-6-phosphate isomerase & AJ620617.1 & CATTCACCAGGGCACCAAGA & TGATCGGAGACGATGTTGCC & 426 \\
Glucose-6-phosphate dehydrogenase & DQ449770.1 & ATGTCGGAGAGCAGTCTCA & CTCCTTCCCGAGTAGTGGT & 765 \\
Phosphoglucomutase & KJ643214.1 & GGAGACGGTTAAGATTACGCAC & TATGCTTCATCGCGGGGT & 413 \\
Mannose phosphate isomerase & DQ449737.1 & TTTGGGAGTTGGGGTAGG & CTCGCTGCTCTTCTTCTCGT & 864 \\
\hline
\end{tabular}


g6pdh and mpi genes. For each of these isolates/strains, we concatenated those sequences to obtain a 3578 bp-long sequence. A maximum likelihood tree was constructed from the concatenated nucleotide dataset using PhyML 3.0 [27]. The best-fit substitution model was determined by the Akaike information criterion (AIC) using Smart Model Selection [28]. The optimal model of evolution was GTR $+\mathrm{I}$ with proportion of invariable sites of 0.989 and one category for substitution rate. Bootstrap values were calculated from 100 replications. The tree was visualized using iTOL [29].

Real-time PCR and high resolution melting (HRM) analysis A $111 \mathrm{bp}$ internal region of the me gene encompassing the single nucleotide polymorphism (SNP) $390 \mathrm{~T}>\mathrm{G}$ was amplified with primers listed in Table 2. Real-time PCR (named qPCR-MEint) was carried out in a $25 \mu \mathrm{l}$ volume with $1 \mu$ template DNA and SYBR green PCR master mix (Diatheva s.r.l.) containing 1U Taq Polymerase and 200 $\mathrm{nM}$ of each primer. The PCR reactions were performed in a Rotor-Gene 6000 instrument (Corbett Life Science, Mortlake, Australia). The amplification profile was: $94{ }^{\circ} \mathrm{C}$ for $10 \mathrm{~min}$; followed by 33 cycles at $94{ }^{\circ} \mathrm{C}$ for $30 \mathrm{~s}, 60{ }^{\circ} \mathrm{C}$ for $20 \mathrm{~s}$ and $72{ }^{\circ} \mathrm{C}$ for $20 \mathrm{~s}$. The reactions were performed in duplicate. After amplification, the high-resolution melting (HRM) analysis was performed over the range $85-95^{\circ}$ $\mathrm{C}$, rising by $0.1{ }^{\circ} \mathrm{C} / \mathrm{s}$ and waiting for $2 \mathrm{~s}$ at each temperature. Raw HRM curves were normalized by the Rotorgene 6000 v.1.7 software. Difference graphs of the normalized curves were obtained using $M H O M / F R / 78$ / LEM75 and MHOM/DZ/82/LIPA59 strains as reference curves for genotypes $390 \mathrm{~T}$ and $390 \mathrm{G}$, respectively.

The qPCR-MEint and HRM analysis was also tested using DNA extracted from 4 clinical samples (whole blood, buffy coat, conjunctival swabs, bone marrow aspirate) as described previously [30, 31]. To ensure adequate sensitivity with these samples, a pre-amplification step (10 cycles) was performed and $2 \mu \mathrm{l}$ of pre-amplified mixture were used as template in the qPCR described above.

\section{Results}

\section{Sequence analyses}

The $L$. infantum isolates/strains gave single products of expected size with the primer pairs listed in Table 2. The PCR products were sequenced and the sequences were aligned with those obtained from GenBank. Partial sequences of $m e, p g d, i c d, g p i, g 6 p d h, m p i$ and pgm genes were obtained from 11 strains/isolates of $L$. infantum. Seven represented MON-1 zymodeme and the remaining four represented MON-24, MON-29, MON-72 and MON-201 (Table 1). Notably, the following L. infantum sequences from zymodemes not previously reported in the databases were obtained: me sequences from
MON-24, MON-72 and MON-201; a pgd sequence from MON-201; icd sequences from MON-24, MON-72 and MON-201; gpi sequences from MON-24, MON-72 and MON-201; g6pdh sequences from MON-24, MON-72 and MON-201; mpi sequences from MON-24, MON-72 and MON-201; and pgm sequences from MON-1, MON-24, MON-29, MON-72 and MON-201.

Concerning the me gene, 13 SNPs were evidenced (Table 3). Nine were silent and four changed the amino acid sequence (V59M; I133S; V330I; E563E/D). These data confirmed previously reported findings obtained with L. donovani complex [19]. All sequences from MON-1 strains were identical, except for the MHOM/TN/80/IPT1 strain. Notably, the genotype heterogeneity of this strain was previously confirmed on the gpi sequence [18]. It is also noteworthy that the two MON-29 strains (MHOM/ ES/82/BCN1 and MHOM/FR/1996/LEM3249) showed differences at nucleotide positions 327, 329 and 507, confirming the higher discriminatory power of a sequencing approach compared to MLEE. The pgd gene sequence showed only the silent SNP 678A $>$ G in 11 strains (Table 4). Concerning the icd gene, it is of relevance that two silent SNPs $(204 \mathrm{~T}>\mathrm{C}, 369 \mathrm{~T}>\mathrm{C})$ were evidenced in strain MHOM/DZ/82/LIPA59 (MON-24) and three silent SNPs (150G $>\mathrm{A}, 369 \mathrm{~T}>\mathrm{C}, 1038 \mathrm{C}>\mathrm{A})$ in strain $\mathrm{MHOM} / \mathrm{SD} / 1997 /$ LEM3472 (MON-267) (Table 5). The polymorphisms $204 \mathrm{~T}>\mathrm{C}$ and $1038 \mathrm{C}>\mathrm{A}$ appeared unique for MON-24 and MON-267, respectively. The gpi gene sequence showed $1503 \mathrm{G}>\mathrm{T} / \mathrm{K}$ and $1831 \mathrm{G}>\mathrm{A} / \mathrm{R}$ SNPs in 4 and 5 strains, respectively (Table 6). The g6pdh gene showed 8 SNPs (Table 7). The mpi gene showed 5 SNPs (Table 8), with SNP 486G>A unique for MON-136. Finally, concerning the pgm gene, no differences were found among the zymodemes examined, including the two sequences available in the database.

The concatenated partial sequences for me, pgd, icd, gpi, g6pdh, mpi from 23 strains were used for phylogenetic tree construction (Fig. 1, Additional file 2: Table S1). The tree showed a $100 \%$ bootstrap support for the $L$. infantum strains and a $75 \%$ support for the clade including all strains of MON-1, 72, 201 zymodemes. Within this clade, the $\mathrm{MHOM} / \mathrm{TN} / 80 / \mathrm{IPT} 1$ strain differed from the bulk of closely related strains (bootstrap support value of 66\%) (Fig. 1). This made it possible to identify the most common genotypes in Europe using a simple screening method (see below).

\section{Exploiting sequence polymorphisms for typing}

As shown in Fig. 1, the clade including zymodemes MON-1, 72, 201 could be discriminated from all other zymodemes with the exception of the MHOM/TN/80/ IPT1 strain. The sequence comparison analysis showed that this group could be discriminated by exploiting the polymorphism $390 \mathrm{~T}>\mathrm{G}$ in the me gene sequence (Table 3). In fact, MON-1, 72, 201 present a $\mathrm{T}$ in position 390 (genotype 
Table 3 Polymorphisms in malic enzyme (me) gene

\begin{tabular}{|c|c|c|c|c|c|c|c|c|c|c|c|c|c|c|c|}
\hline Zymodeme & Strain/isolate & GenBank ID & 106 & 204 & 327 & 329 & 390 & 507 & 586 & 762 & 843 & 919 & 1182 & 1287 & 1620 \\
\hline$\overline{\mathrm{MON}-1}$ & MHOM/FR/78/LEM75 & DQ449701.1 & $G$ & $C$ & $C$ & $\bar{T}$ & $\bar{T}$ & $\bar{T}$ & $C$ & C & C & $G$ & $A$ & $C$ & G \\
\hline MON-1 & MHOM/ES/1993/PM1 & DQ449703.1 & . & . & . & . & . & . & . & . & . & . & . & . & . \\
\hline MON-1 & MHOM/FR/1995/LPN114 & DQ449702.1 & . & . & . & . & . & . & . & . & . & . & . & . & . \\
\hline MON-1 & MHOM/PT/2000/IMT260 & DQ449706.1 & . & . & . & . & . & . & . & . & . & . & . & . & . \\
\hline MON-1 & MHOM/FR/1997/LSL29 & DQ449704.1 & . & . & . & . & . & . & . & . & . & . & . & . & . \\
\hline MON-1 & MHOM/ES/1986/BCN16 & DQ449705.1 & . & . & . & . & . & . & . & . & . & . & . & . & . \\
\hline MON-1 & MHOM/BL/67/ITMAP263 & KU175196.1 & . & . & . & . & . & . & . & . & . & . & . & . & - \\
\hline MON-1 & MHOM/TN/80/IPT1 & MF375413 & - & . & . & . & G & . & . & . & . & - & - & - & - \\
\hline MON-1 & MHOM/FR/78/LEM75 & MF375414 & - & . & . & . & . & . & . & . & . & - & - & - & - \\
\hline MON-1 & Isolate $31 \mathrm{U}$ & MF375415 & - & . & . & . & . & . & . & . & . & - & - & - & - \\
\hline MON-1 & Isolate $49 u$ & MF375416 & - & . & . & . & . & . & - & . & . & - & - & - & - \\
\hline MON-1 & Isolate 10816 & MF375417 & - & . & . & . & . & . & . & . & . & - & - & - & - \\
\hline MON-1 & Isolate 791 & MF375418 & - & . & . & . & . & . & . & . & . & - & - & - & - \\
\hline MON-1 & Isolate V2921 & MF375419 & - & - & - & - & - & - & - & . & . & - & - & - & - \\
\hline MON-11 & MHOM/FR/1980/LEM189 & DQ449714.1 & . & . & . & . & G & . & . & . & . & . & . & . & . \\
\hline MON-24 & MHOM/DZ/82/LIPA59 & MF375420 & - & $\mathrm{T}$ & . & G & G & G & . & . & $\mathrm{T}$ & - & - & - & - \\
\hline MON-29 & MHOM/ES/82/BCN1 & MF375421 & - & . & M & G & G & G & . & . & . & - & - & - & - \\
\hline MON-29 & MHOM/FR/1996/LEM3249 & DQ449707.1 & . & . & . & . & G & . & . & . & . & . & . & . & . \\
\hline MON-72 & MHOM/IT/86/ISS218 & MF375422 & - & . & . & . & . & . & . & . & . & . & . & . & - \\
\hline MON-78 & MHOM/MT/1985/BUCK & DQ449715.1 & - & . & . & G & G & G & . & . & . & A & C & $\mathrm{T}$ & . \\
\hline MON-81 & MHOM/SD/1962/35 & DQ449718.1 & - & . & . & G & G & G & A & G & . & A & . & . & . \\
\hline MON-98 & MHOM/GR/2001/GH6 & DQ449728.1 & . & . & . & . & G & . & . & . & . & . & . & . & . \\
\hline MON-98 & MCAN/GR/2001/GD8 & DQ449729.1 & . & . & . & . & G & . & . & . & . & . & . & . & . \\
\hline MON-98 & MHOM/GR/2003/GH15 & DQ449730.1 & . & . & . & . & G & . & . & . & . & . & . & . & . \\
\hline MON-98 & MHOM/GR/2003/GH16 & DQ449731.1 & . & . & . & . & G & . & . & . & . & . & . & . & . \\
\hline MON-98 & MHOM/GR/2003/GH18 & DQ449732.1 & . & . & . & . & G & . & . & . & . & . & . & . & . \\
\hline MON-98 & MHOM/GR/2003/GH2O & DQ449733.1 & . & . & . & . & G & . & . & . & . & . & . & . & . \\
\hline MON-98 & MHOM/GR/2004/GD17 & DQ449734.1 & . & . & . & . & G & . & . & . & . & . & . & . & . \\
\hline MON-183 & MHOM/ES/1991/LEM2298 & DQ449708.1 & . & . & . & . & G & . & . & . & . & . & . & . & . \\
\hline MON-188 & MHOM/IT/1993/ISS800 & DQ449722.1 & . & $\mathrm{T}$ & . & G & G & G & . & . & $\mathrm{T}$ & A & . & . & . \\
\hline MON-198 & MHOM/ES/1988/LLM175 & DQ449719.1 & . & . & . & . & G & . & . & . & . & . & . & . & . \\
\hline MON-199 & MHOM/ES/1992/LLM373 & DQ449720.1 & A & . & . & G & G & G & . & . & . & . & C & . & . \\
\hline MON-201 & MHOM/IT/93/ISS822 & MF375423 & . & . & . & . & . & . & . & . & . & . & . & . & - \\
\hline MON-228 & MHOM/IT/1994/ISS1036 & DQ449721.1 & . & . & . & . & G & . & . & . & . & . & . & . & $S$ \\
\hline MON-267 & MHOM/SD/1997/LEM3472a & DQ449723.1 & . & . & . & G & G & G & . & . & . & A & . & . & . \\
\hline MON-309 & ITOB/TR/2005/CUK2 & EU545253.1 & . & $\mathrm{T}$ & . & K & G & G & . & . & Y & A & . & . & . \\
\hline MON-309 & MHOM/TR/2005/CUK1 & EU545252.1 & . & $\mathrm{T}$ & . & G & G & G & . & . & $\mathrm{T}$ & A & . & . & . \\
\hline ni & ITOB/TR/2007/CUK10 & EU545254.1 & . & $\mathrm{T}$ & . & K & G & G & . & . & Y & A & . & . & . \\
\hline non-MON-1 & MHOM/TR/2000/OG-VL & EU545255.1 & . & · & . & . & G & - & . & . & . & . & . & . & · \\
\hline ni & Isolate RRR-B & DQ449727.1 & . & . & . & . & G & . & . & . & . & . & . & . & . \\
\hline
\end{tabular}

Zymodeme sequences obtained in this study are in bold

Abbreviation: $n i$ not indicated

Key: . consensus sequence, - sequence not available

anitially assigned to $L$. infantum and successively designated L. donovani [18] 
Table 4 Polymorphisms in 6-phosphogluconate dehydrogenase (pgd)

\begin{tabular}{|c|c|c|c|c|c|}
\hline Zymodeme & Strain/isolate & GenBank ID & 194 & 678 & 747 \\
\hline $\mathrm{MON}-1$ & MHOM/FR/78/LEM75 & AM157139.1 & C & A & C \\
\hline $\mathrm{MON}-1$ & MHOM/PT/2000/IMT260 (LEM3975) & AM157144.1 & . & . & . \\
\hline $\mathrm{MON}-1$ & MHOM/ES/1986/BCN16 (LEM1078) & AM157143.1 & . & . & . \\
\hline MON-1 & MHOM/FR/1997/LSL29 (LEM3420) & AM157142.1 & . & . & . \\
\hline $\mathrm{MON}-1$ & MHOM/ES/1993/PM1 (LEM2608) & AM157141.1 & . & . & . \\
\hline $\mathrm{MON}-1$ & MHOM/FR/1995/LPN114 (LEM3001) & AM157140.1 & . & . & . \\
\hline MON-1 & MHOM/TN/1980/IPT1 & AM157736.1 & . & . & . \\
\hline MON-1 & MHOM/TN/1980/IPT1 & MF280205 & - & . & . \\
\hline MON-1 & Isolate $31 \mathrm{u}$ & MF280206 & - & . & . \\
\hline MON-1 & Isolate $49 u$ & MF280207 & - & . & . \\
\hline MON-1 & Isolate 791 & MF280208 & - & . & . \\
\hline MON-1 & Isolate 10816 & MF280209 & - & . & . \\
\hline MON-1 & MHOM/FR/78/LEM75 & MF2802010 & - & . & . \\
\hline MON-1 & Isolate V2921 & MF2802011 & - & . & . \\
\hline MON-11 & MHOM/FR/1980/LEM189 & AM157151.1 & . & G & . \\
\hline MON-24 & MHOM/DZ/82/LIPA59 & MF2802012 & - & G & . \\
\hline MON-24 & IARI/PT/1989/IMT171 & AM157137.1 & . & G & . \\
\hline MON-27 & MHOM/IT/1979/Francesca & AM157138.1 & . & . & . \\
\hline MON-29 & MHOM/ES/82/BCN1 & MF2802013 & - & G & . \\
\hline MON-29 & MHOM/FR/1996/LEM3249 & AM157145.1 & . & G & . \\
\hline MON-34 & MHOM/CN/1980/A & AM157136.1 & . & G & . \\
\hline MON-72 & MHOM/IT/86/ISS218 & MF2802014 & - & . & . \\
\hline MON-78 & MHOM/MT/1985/BUCK & AM157152.1 & . & . & . \\
\hline MON-81 & MHOM/SD/1962/3S & AM157155.1 & $\mathrm{T}$ & G & $\mathrm{T}$ \\
\hline MON-183 & MHOM/ES/1991/LEM2298 & AM157146.1 & . & G & . \\
\hline MON-188 & MHOM/IT/1993/ISS800 & AM157159.1 & . & G & . \\
\hline MON-198 & MHOM/ES/1988/LLM175 & AM157156.1 & . & G & . \\
\hline MON-199 & MHOM/ES/1992/LLM373 & AM157157.1 & . & G & . \\
\hline MON-201 & MHOM/IT/93/ISS822 & MF2802015 & - & . & . \\
\hline MON-228 & MHOM/IT/1994/ISS1036 & AM157158.1 & . & G & . \\
\hline MON-267 & MHOM/SD/1997/LEM3472a & AM157160.1 & $\mathrm{T}$ & G & $\mathrm{T}$ \\
\hline
\end{tabular}

Zymodeme sequences obtained in this study are in bold

Key: . consensus sequence, - sequence not available

anitially assigned to $L$. infantum and successively designated L. donovani [18]

390T), while the other zymodemes present a G (genotype 390G). Due to this observation, we developed a HRMbased assay to monitor the SNP at position 390. To this end, two internal primers were designed upstream and downstream nucleotide 390, and used for a new qPCR assay (qPCR-MEint) (Additional file 1: Figure S1a). The qPCR-MEint showed a linear correlation between the log of DNA concentration (from 2 to $2 \times 10^{-5} \mathrm{ng} /$ reaction) and Ct values, with a reaction efficiency of $90 \%$ (Fig. 2).

HRM analysis allowed us to distinguish amplicons with genotype 390G (i.e. MHOM/TN/80/IPT1 and MHOM/ DZ/82/LIPA59 strains) from amplicons with genotype
390T (i.e. MHOM/FR/78/LEM75 and MHOM/IT/86/ ISS218 strains) (Fig. 3a). Furthermore, using the PCR product from strains MHOM/DZ/82/LIPA59 and MHOM/FR/78/LEM75 as reference, two L. infantum clinical isolates (isolate 1 and 2) [32] were typed with qPCR-MEint followed by HRM analysis. The HRM analysis tool of Rotor-Gene 6000 software allowed for the assignment of amplicons of clinical isolate 1 and 2 to genotype 390G and genotype 390T, respectively, with a confidence $>95 \%$ in at least one replicate (Fig. 3b). These results have been confirmed by PCR product sequencing (Additional file 3: Figure S2). 
Table 5 Polymorphisms in mitochondrial isocitrate dehydrogenase (icd)

\begin{tabular}{|c|c|c|c|c|c|c|}
\hline Zymodeme & Strain/isolate & GenBank ID & 150 & 204 & 369 & 1038 \\
\hline $\mathrm{MON}-1$ & MHOM/FR/78/LEM75 & DQ449672.1 & G & $\mathrm{T}$ & $\mathrm{T}$ & $C$ \\
\hline MON-1 & MHOM/ES/1986/BCN16 & DQ449676.1 & . & . & . & . \\
\hline MON-1 & MHOM/FR/1997/LSL29 & DQ449675.1 & . & . & . & . \\
\hline $\mathrm{MON}-1$ & MHOM/ES/1993/PM1 & DQ449674.1 & . & . & . & . \\
\hline $\mathrm{MON}-1$ & MHOM/FR/1995/LPN114 & DQ449673.1| & . & . & . & . \\
\hline MON-1 & MHOM/PT/2000/IMT260 & DQ449677.1 & . & . & . & . \\
\hline MON-1 & MHOM/TN/1980/IPT1 & MF347625 & . & . & . & - \\
\hline MON-1 & MHOM/FR/78/LEM75 & MF347626 & . & . & . & - \\
\hline MON-1 & Isolate $31 \mathrm{u}$ & MF347627 & . & . & . & - \\
\hline MON-1 & Isolate $49 u$ & MF347628 & . & . & . & - \\
\hline MON-1 & Isolate 791 & MF347629 & . & . & . & - \\
\hline MON-1 & Isolate 10816 & MF347630 & . & . & . & - \\
\hline MON-1 & Isolate V2921 & MF347631 & . & . & . & - \\
\hline MON-11 & MHOM/FR/1980/LEM189 & DQ449685.1 & . & . & C & . \\
\hline MON-24 & MHOM/DZ/82/LIPA59 & MF347632 & . & C & C & - \\
\hline MON-29 & MHOM/ES/82/BCN1 & MF347633 & . & . & . & - \\
\hline MON-29 & MHOM/FR/1996/LEM3249 & DQ449678.1 & . & . & C & . \\
\hline MON-72 & MHOM/IT/86/ISS218 & MF347634 & . & . & . & - \\
\hline MON-78 & MHOM/MT/1985/BUCK & DQ449686.1 & . & . & C & . \\
\hline MON-81 & $\mathrm{MHOM} / \mathrm{SD} / 1962 / 3 \mathrm{~S}^{\mathrm{a}}$ & DQ449689.1 & A & . & C & . \\
\hline MON-183 & MHOM/ES/1991/LEM2298 & DQ449679.1 & . & . & . & . \\
\hline MON-188 & MHOM/IT/1993/ISS800 & DQ449693.1 & . & . & C & . \\
\hline MON-198 & MHOM/ES/1988/LLM175 & DQ449690.1 & . & . & . & . \\
\hline MON-199 & MHOM/ES/1992/LLM373 & DQ449691.1 & . & . & . & . \\
\hline MON-201 & MHOM/IT/93/ISS822 & MF347635 & . & . & . & - \\
\hline MON-228 & MHOM/IT/1994/ISS1036 & DQ449692.1 & . & . & C & . \\
\hline MON-267 & MHOM/SD/1997/LEM3472a & DQ449694.1 & A & . & $C$ & A \\
\hline MON-309 & ITOB/TR/2005/CUK2 & EU545241.1 & . & . & C & . \\
\hline MON-309 & MHOM/TR/2005/CUK1 & EU545240.1 & . & . & C & . \\
\hline ni & ITOB/TR/2007/CUK10 & EU545242.1 & . & . & C & . \\
\hline non-MON-1 & MHOM/TR/2000/OG-VL & EU545243.1 & . & . & . & . \\
\hline ni & ni & DQ449698.1 & . & . & . & . \\
\hline
\end{tabular}

Zymodeme sequences obtained in this study are in bold

Abbreviation: $n i$ not indicated

Key: . consensus sequence, - sequence not available

${ }^{a}$ Initially assigned to $L$. infantum and successively designated $L$. donovani [18]

\section{Application of HRM analysis in clinical samples}

To test the feasibility of the HRM-based typing approach without parasite cultivation, the qPCR-MEint followed by HRM analysis was performed using DNA extracted from canine clinical samples $[31,33]$ and a human clinical sample (blood), using PCR product from strains MHOM/DZ/82/LIPA59 and MHOM/FR/78/LEM75 as reference. The human peripheral venous blood sample was obtained during routine diagnosis of a patient with VL by venipuncture of the upper limb. The HRM analysis allowed for the assignment of all samples to group 390T (Table 9). The results were confirmed by PCR product sequencing (Additional file 4: Figure S3).

\section{Discussion}

Epidemiological studies examining the dynamic balance between host, vector, and pathogen populations is an important aspect of Leishmania infections, and the importance of reservoirs alternative to the canine population (e.g. lagomorphs, wolves) is currently being investigated 
Table 6 Polymorphisms in glucose-6-phosphate isomerase (gpi)

\begin{tabular}{|c|c|c|c|c|c|c|}
\hline Zymodeme & Strain/isolate & GenBank ID & 703 & 1503 & 1807 & 1831 \\
\hline $\mathrm{MON}-1$ & MHOM/FR/1978/LEM75 & AJ620617.1 & $T$ & G & C & G \\
\hline MON-1 & MHOM/TN/1980/IPT1 & AJ620647.1 & . & . & . & A \\
\hline $\mathrm{MON}-1$ & MHOM/PT/2000/IMT260 & AM157725.1 & . & . & . & . \\
\hline $\mathrm{MON}-1$ & MHOM/ES/1986/BCN16 & AM157724.1 & . & . & . & . \\
\hline $\mathrm{MON}-1$ & MHOM/FR/1997/LSL29 & AM157723.1 & . & . & . & . \\
\hline $\mathrm{MON}-1$ & MHOM/ES/1993/PM1 & AM157722.1 & . & . & . & . \\
\hline MON-1 & MHOM/FR/1995/LPN114 & AM157721.1 & . & . & . & . \\
\hline MON-1 & MHOM/TN/1980/IPT1 & MF288905 & - & . & - & - \\
\hline MON-1 & MHOM/FR/78/LEM75 & MF288906 & - & . & - & - \\
\hline MON-1 & Isolate $31 \mathrm{u}$ & MF288907 & - & . & - & - \\
\hline MON-1 & Isolate $49 u$ & MF288908 & - & . & - & - \\
\hline MON-1 & Isolate 791 & MF288909 & - & . & - & - \\
\hline MON-1 & Isolate 10816 & MF288910 & - & . & - & - \\
\hline MON-1 & Isolate V2921 & MF288911 & - & . & - & - \\
\hline MON-24 & MHOM/DZ/82/LIPA59 & MF288912 & - & . & - & - \\
\hline MON-27 & MHOM/IT/1979/Francesca & AM117192.1 & . & . & . & $\mathrm{R}$ \\
\hline MON-29 & MHOM/ES/82/BCN1 & MF288913 & - & . & - & - \\
\hline MON-29 & MHOM/FR/1996/LEM3249 & AJ620618.1 & . & . & . & . \\
\hline MON-34 & MHOM/CN/1980/A & AJ620637.1 & . & . & . & A \\
\hline MON-72 & MHOM/IT/86/ISS218 & MF288914 & - & . & - & - \\
\hline MON-78 & MHOM/MT/1985/BUCK & AJ620619.1 & . & . & . & A \\
\hline MON-81 & MHOM/SD/1962/3S & AJ620629.1 & C & . & $\mathrm{T}$ & . \\
\hline MON-183 & MHOM/ES/1991/LEM2298 & AJ620620.1 & . & $\mathrm{T}$ & . & . \\
\hline MON-198 & MHOM/ES/1988/LLM175 & AJ620630.1 & . & $\mathrm{T}$ & . & . \\
\hline MON-199 & MHOM/ES/1992/LLM373 & AJ620631.1 & . & $\mathrm{T}$ & . & $\mathrm{R}$ \\
\hline MON-201 & MHOM/IT/93/ISS822 & MF288915 & - & . & - & - \\
\hline MON-228 & MHOM/IT/1994/ISS1036 & AJ620632.1 & . & K & . & . \\
\hline MON-267 & MHOM/SD/1997/LEM3472a & AJ620634.1 & C & . & $\mathrm{T}$ & . \\
\hline
\end{tabular}

Zymodeme sequences obtained in this study are in bold

Key: . consensus sequence, - sequence not available

anitially assigned to $L$. infantum and successively designated $L$. donovani [18]

[34, 35]. For example, in Italy, L. infantum zymodemes retrieved in infected dogs are primarily represented by MON-1 and MON-72, while infection in humans is caused by a more heterogeneous zymodeme population, suggesting that the canine population is not the only reservoir for all L. infantum zymodemes [15].

In this study, we investigated the genetic diversity within seven L. infantum genes, aiming to provide information that could aid in the development of tools for fast genetic characterization and epidemiological screening of $L$. infantum in mammalian host and/or vectors. In particular, we investigated whether it was possible to distinguish the genotype associated with the most common zymodemes in the Mediterranean area (i.e. MON-1 and MON-72), from the genotype associated with all other zymodemes, therefore limiting the number of samples needing costly and time-consuming characterizations. To this end, we collected and aligned all $L$. infantum gene sequences of seven enzymes ( $m e, p g d, i c d, g p i$, g6pdh, mpi, pgm) available in GenBank to identify the regions that were more polymorphic. These regions were amplified in 11 other L. infantum strains available in our laboratory to increase the number of sequences to compare. The phylogenetic analysis of the concatenated sequences showed that the group including zymodemes MON-1, 72, 201 clustered separately. Zymodeme MON201 has been found only in some HIV-positive individuals [12, 36] and in one case of feline leishmaniasis [37]; therefore, its retrieval may be considered rare. Notably, the genetic distance of MON-81 and MON-267 from other L. infantum zymodemes was confirmed (Fig. 1, Additional file 2: Table S1). In fact, MON-81 and 
Table 7 Polymorphisms in glucose-6-phosphate dehydrogenase ( $g 6 p d h$ )

\begin{tabular}{|c|c|c|c|c|c|c|c|c|c|c|}
\hline Zymodeme & Strain/isolate & GenBank ID & 45 & 315 & 348 & 359 & 403 & 468 & 690 & 1191 \\
\hline $\mathrm{MON}-1$ & MHOM/FR/78/LEM75 & DQ449770.1 & $\mathrm{T}$ & C & $\mathrm{T}$ & A & G & $\mathrm{T}$ & C & C \\
\hline MON-1 & MHOM/PT/2000/IMT260 & DQ449775.1 & . & . & . & . & . & . & . & . \\
\hline MON-1 & MHOM/ES/1986/BCN16 & DQ449774.1 & . & . & . & . & . & . & . & . \\
\hline MON-1 & MHOM/FR/1997/LSL29 & DQ449773.1 & . & . & . & W & . & . & . & . \\
\hline MON-1 & MHOM/ES/1993/PM1 & DQ449772.1 & . & . & . & . & . & . & . & . \\
\hline $\mathrm{MON}-1$ & MHOM/FR/1995/LPN114 & DQ449771.1 & . & . & . & . & . & . & . & . \\
\hline MON-1 & MHOM/BL/67/ITMAP263 & KU175220.1 & - & . & . & . & . & . & . & . \\
\hline MON-1 & MHOM/TN/80/IPT1 & MF479731 & . & . & . & . & . & . & . & - \\
\hline MON-1 & MHOM/FR/78/LEM75 & MF479732 & . & - & - & - & - & . & . & - \\
\hline MON-1 & Isolate $49 u$ & MF479733 & . & . & . & . & . & . & . & - \\
\hline MON-1 & Isolate $31 \mathrm{U}$ & MF479734 & . & . & . & - & - & - & . & - \\
\hline MON-1 & Isolate 791 & MF479735 & . & . & . & . & . & . & . & - \\
\hline MON-1 & Isolate 10816 & MF479736 & . & . & . & . & . & . & . & - \\
\hline MON-1 & Isolate V2921 & MF479737 & . & . & . & . & . & . & . & - \\
\hline MON-11 & MHOM/FR/1980/LEM189 & DQ449783.1 & C & . & . & T & . & . & . & . \\
\hline MON-24 & MHOM/DZ/82/LIPA59 & MF479738 & C & . & . & . & . & . & . & - \\
\hline MON-29 & MHOM/ES/82/BCN1 & MF479739 & C & . & . & $\mathrm{T}$ & . & . & . & - \\
\hline MON-29 & MHOM/FR/1996/LEM3249 & DQ449776.1 & C & . & . & W & . & . & . & - \\
\hline MON-72 & MHOM/IT/86/ISS218 & MF479740 & . & . & . & . & . & . & . & - \\
\hline MON-77 & MCAM/ES/86/LEM935 & DQ449797.1 & . & . & . & W & . & . & . & - \\
\hline MON-78 & MHOM/MT/1985/BUCK & DQ449784.1 & C & . & . & . & . & . & . & . \\
\hline MON-81 & $\mathrm{MHOM} / \mathrm{SD} / 1962 / 3 \mathrm{~S}^{\mathrm{a}}$ & DQ449787.1 & C & G & C & . & . & . & $\mathrm{T}$ & $\mathrm{T}$ \\
\hline MON 105 & MHOM/ES/2001/LLM1026 & DQ449799.1 & . & . & . & . & . & . & . & . \\
\hline MON-183 & MHOM/ES/1991/LEM2298 & DQ449777.1 & . & . & . & W & . & . & . & . \\
\hline MON-188 & MHOM/IT/1993/ISS800 & DQ449791.1 & C & . & . & . & . & . & . & . \\
\hline MON-198 & MHOM/ES/1988/LLM175 & DQ449788.1 & C & . & . & $\mathrm{T}$ & . & . & . & . \\
\hline MON-199 & MHOM/ES/1992/LLM373 & DQ449789.1 & . & . & . & W & . & . & . & . \\
\hline MON-201 & MHOM/IT/93/ISS822 & MF479741 & . & . & . & . & . & . & . & . \\
\hline MON-228 & MHOM/IT/1994/ISS1036 & DQ449790.1 & . & . & . & . & . & . & . & . \\
\hline MON-253 & MHOM/ES/1996/LLM580 & DQ449798.1 & . & . & . & . & A & . & . & . \\
\hline MON-267 & MHOM/SD/1997/LEM3472 & DQ449792.1 & C & G & C & . & . & . & $\mathrm{T}$ & $\mathrm{T}$ \\
\hline MON-267 & MCAN/SD/2000/LEM3988 & KU175214.1 & - & G & C & . & . & . & $\mathrm{T}$ & . \\
\hline MON-309 & ITOB/TR/2005/CUK2 & EU545237.1 & C & . & . & . & . & . & . & . \\
\hline MON-309 & MHOM/TR/2005/CUK1 & EU545236.1 & C & . & . & . & . & . & . & . \\
\hline ni & ITOB/TR/2007/CUK10 & EU545238.1 & C & . & . & . & . & . & . & . \\
\hline ni & MHOM/CN/93/KXG-XU & JX021334.1 & - & . & C & . & . & C & . & . \\
\hline ni & MHOM/CN/94/KXG-LIU & JX021333.1 & - & . & C & . & . & C & . & $\cdot$ \\
\hline non-MON-1 & MHOM/TR/2000/OG-VL & EU545239.1 & . & . & . & . & . & . & . & . \\
\hline ni & Isolate RRR-B & DQ449796.1 & . & . & . & . & . & . & . & . \\
\hline ni & MHOM/PA/78/WR285 & KU175216.1 & - & . & . & . & . & . & . & . \\
\hline ni & Isolate D38 & KU175221.1 & - & . & . & . & . & . & . & . \\
\hline ni & Isolate D33 & KU175219.1 & - & . & . & . & . & . & . & . \\
\hline ni & Isolate D36D & KU175218.1 & - & . & . & . & . & . & . & . \\
\hline ni & Isolate E9D & KU175217.1 & - & . & . & . & . & . & . & . \\
\hline
\end{tabular}


Table 7 Polymorphisms in glucose-6-phosphate dehydrogenase (g6pdh) (Continued)

\begin{tabular}{llllllllll}
\hline Zymodeme & Strain/isolate & GenBank ID & 45 & 315 & 348 & 359 & 403 & 468 & 690 \\
\hline ni & JPCM5 & XM_001468358.1 & $\cdot$ & $\cdot$ & $\cdot$ & $\cdot$ & $\cdot$ & $\cdot$ & $\cdot$ \\
\hline
\end{tabular}

Zymodeme sequences obtained in this study are in bold

Abbreviation: $n i$ not indicated

Key: . consensus sequence, - sequence not available

${ }^{a}$ Initially assigned to $L$. infantum and successively designated $L$. donovani [18]

Table 8 Polymorphisms in mannose phosphate isomerase (mpi)

\begin{tabular}{|c|c|c|c|c|c|c|c|}
\hline Zymodeme & Strain/isolate & GenBank ID & 300 & 392 & 486 & 637 & 798 \\
\hline $\mathrm{MON}-1$ & MHOM/FR/1978/LEM75 & DQ449737.1 & C & A & G & A & C \\
\hline $\mathrm{MON}-1$ & MHOM/FR/1995/LPN114 & DQ449738.1 & . & . & . & . & . \\
\hline $\mathrm{MON}-1$ & MHOM/ES/1993/PM1 & DQ449739.1 & . & . & . & . & . \\
\hline $\mathrm{MON}-1$ & MHOM/FR/1997/LSL29 & DQ449740.1 & . & . & . & . & . \\
\hline $\mathrm{MON}-1$ & MHOM/ES/1986/BCN16 & DQ449741.1 & . & . & . & . & . \\
\hline $\mathrm{MON}-1$ & MHOM/PT/2000/IMT260 & DQ449742.1 & . & . & . & . & . \\
\hline MON-1 & MHOM/TN/1980/IPT1 & MF462101 & . & . & . & . & . \\
\hline MON-1 & MHOM/FR/78/LEM75 & MF462102 & . & - & - & . & . \\
\hline MON-1 & Isolate $31 \mathrm{u}$ & MF462103 & . & . & . & . & . \\
\hline MON-1 & Isolate 791 & MF462104 & . & . & . & . & . \\
\hline MON-1 & Isolate 10816 & MF462105 & . & . & - & . & . \\
\hline MON-1 & Isolate V2921 & MF462106 & . & . & . & . & . \\
\hline MON-1 & Isolate $49 u$ & MF462107 & $\cdot$ & . & . & . & . \\
\hline MON-11 & MHOM/FR/1980/LEM189 & DQ449750.1 & . & . & . & . & . \\
\hline MON-24 & MHOM/DZ/82/LIPA59 & MF462108 & . & . & . & . & . \\
\hline MON-29 & MHOM/ES/81/BCN1 & MF462109 & . & . & . & . & . \\
\hline MON-29 & MHOM/FR/1996/LEM3249 & DQ449743.1 & . & . & . & . & . \\
\hline MON-72 & MHOM/IT/86/ISS218 & MF462110 & . & . & . & . & . \\
\hline MON-78 & MHOM/MT/1985/BUCK & DQ449751.1 & . & . & . & . & . \\
\hline MON-81 & MHOM/SD/1962/3S & DQ449754.1 & . & . & . & . & . \\
\hline MON-136 & MHOM/IT/1990/ISS510 & DQ449766.1 & · & · & A & $\mathrm{R}$ & $\cdot$ \\
\hline MON-183 & MHOM/ES/1991/LEM2298 & DQ449744.1 & . & . & . & . & . \\
\hline MON-188 & MHOM/IT/1993/ISS800 & DQ449758.1 & . & . & . & G & . \\
\hline MON-198 & MHOM/ES/1988/LLM175 & DQ449755.1 & . & . & . & . & . \\
\hline MON-199 & MHOM/ES/1992/LLM373 & DQ449756.1 & . & . & . & . & . \\
\hline MON-201 & MHOM/IT/93/ISS822 & MF462111 & . & . & . & $\mathrm{R}$ & . \\
\hline MON-228 & MHOM/IT/1994/ISS1036 & DQ449757.1 & . & . & . & . & . \\
\hline MON-267 & MHOM/SD/1997/LEM3472a & DQ449759.1 & T & $\mathrm{R}$ & . & . & $\mathrm{T}$ \\
\hline non-MON-1 & MHOM/TR/2000/OG-VL & EU545251.1 & . & . & . & . & . \\
\hline ni & MHOM/TR/2005/CUK1 & EU545248.1 & . & . & . & . & . \\
\hline ni & ITOB/TR/2005/CUK2 & EU545249.1 & . & . & . & . & . \\
\hline ni & ITOB/TR/2007/CUK10 & EU545250.1 & . & . & . & . & . \\
\hline ni & MHOM/CN/94/KXG-LIU & JX021373.1 & T & . & . & . & $\mathrm{T}$ \\
\hline ni & $\mathrm{MHOM} / \mathrm{CN} / 93 / \mathrm{KXG}-\mathrm{XU}$ & $J X 021374.1$ & $\mathrm{~T}$ & . & . & . & $\mathrm{T}$ \\
\hline ni & Isolate RRR-B & DQ449763.1 & Y & . & . & . & Y \\
\hline
\end{tabular}

Zymodeme sequences obtained in this study are in bold

Abbreviation: $n i$ not indicated

Key: . consensus sequence, - sequence not available

anitially assigned to $L$. infantum and successively designated $L$. donovani [18] 
Tree scale: $0.01 \longmapsto$

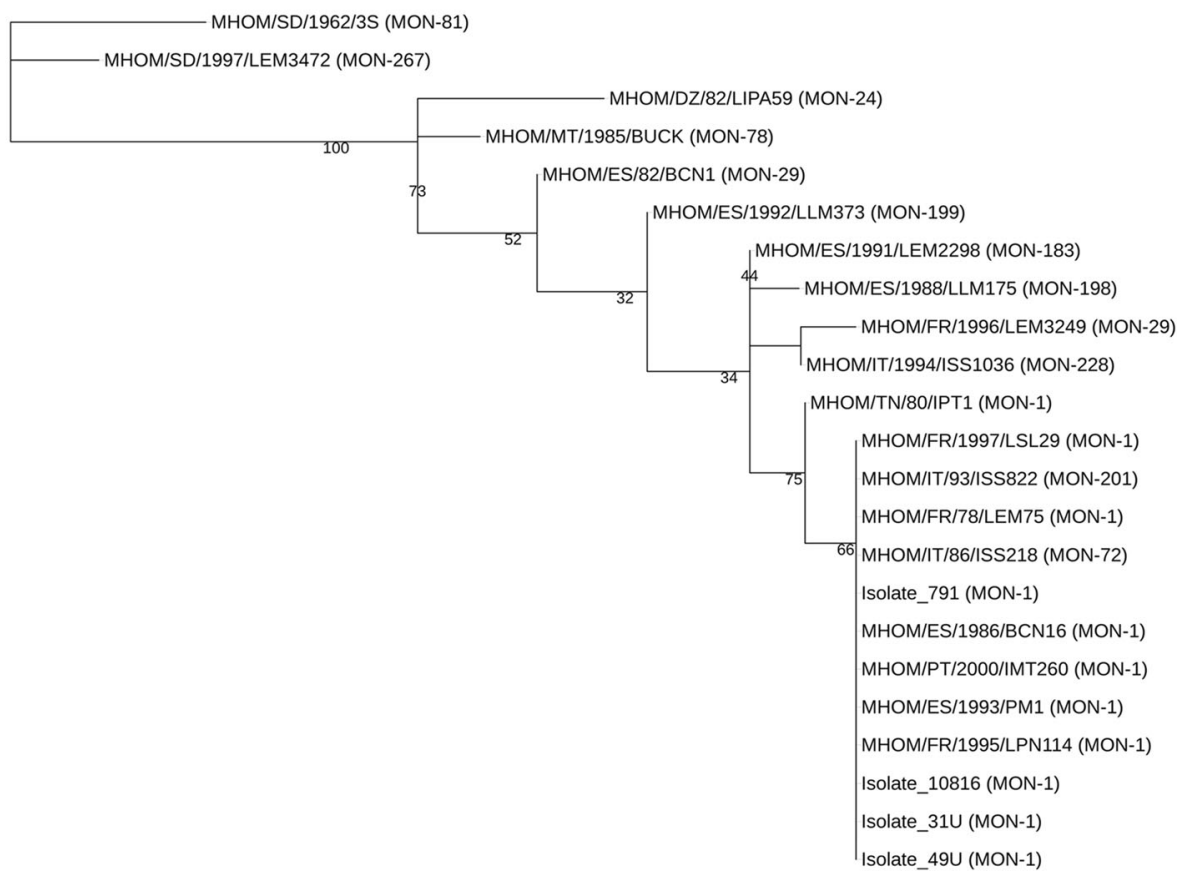

Fig. 1 Phylogenetic tree of 23 strains based on the multilocus sequence data. The sequencing data for six genes (me, pgd, icd, gpi, g6pdh, mpi) were used to build a 3578 bp long sequence. The tree was constructed using the Maximum Likelihood method based on the GTR+I model using PhyML 3.0 software. Bootstrap values were calculated from 100 replications. Numbers below branches represent bootstrap support

MON-267, initially considered L. infantum, have been successively assigned to $L$. donovani [18].

Remarkably, the silent polymorphism at position 390 (T/G) of the me gene distinguishes strains of MON-1, 72, 201 (genotype 390T) from strains of other zymodemes (genotype 390G) (Table 3). This could be important for epidemiological applications, as MON-1 is the most common zymodeme of L. infantum in Europe. The only exception was the reference strain $\mathrm{MHOM} / \mathrm{TN} / 80$ / IPT1, which presents a guanine at nucleotide 390 . This may be due to the geographical origin of this strain (Tunisia) compared to the European strains/isolates. It is also noteworthy that, among the MON-1 strains, only strain $\mathrm{MHOM} / \mathrm{TN} / 80 / \mathrm{IPT} 1$ cannot be distinguished

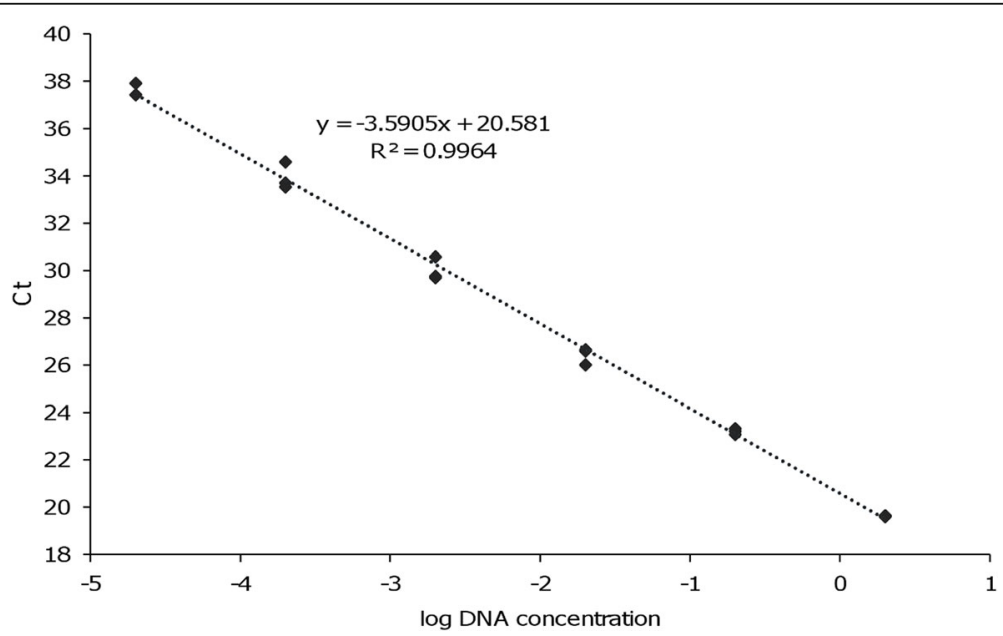

Fig. 2 Linear correlation between the log of DNA concentration and Ct values. The qPCR-MEint curve was obtained amplifying serial dilutions of genomic DNA (from 2 to $2 \times 10^{-5} \mathrm{ng} /$ reaction tube) purified from L. infantum MHOM/FR/78/LEM75 $(y=-3.59 x+20.58)$. Each reaction was performed in triplicate. Reaction efficiency $=90 \%, R^{2}=0.996$ 

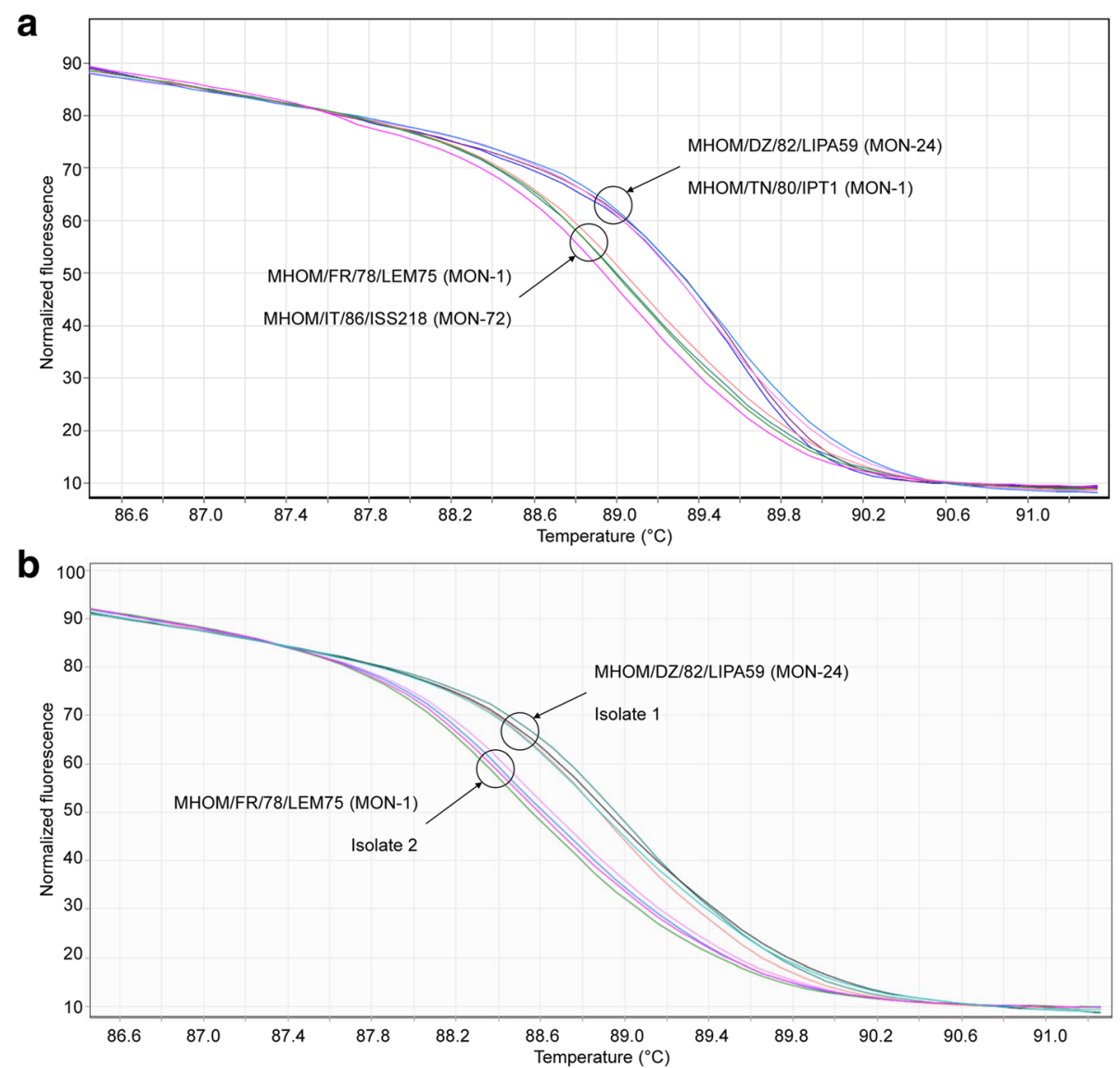

Fig. 3 HRM analysis of amplicons with genotypes 390G and 390T. a HRM profiles obtained from qPCR-MEint amplicons of strains MHOM/TN/80/ IPT1 and MHOM/DZ/82/LIPA59 (genotype 390G) and amplicons of strains MHOM/FR/78/LEM75 and MHOM/IT/86/ISS218 (genotype 390T). b The analysis of HRM profiles allowed the assignation of amplicons of clinical isolates 1 and 2 to genotypes 390G and 390T, respectively, with a confidence > 95\% in at least one replicate. Strains MHOM/DZ/82/LIPA59 (genotype 390G) and MHOM/FR/78/LEM75 (genotype 390T) were used as reference. Analyses were performed in duplicates

Table 9 HRM analysis results of clinical samples

\begin{tabular}{lll}
\hline Name & Genotype & Confidence \% \\
\hline MHOM/FR/78/LEM75 & 390T & 98.02 \\
MHOM/FR/78/LEM75 & 390T & 98.02 \\
MHOM/DZ/82/LIPA59 & 390G & 99.90 \\
MHOM/DZ/82/LIPA59 & 390G & 99.90 \\
$62 \mathrm{bc}$ & 390T & 85.05 \\
$62 \mathrm{bc}$ & 390T & 82.99 \\
$77 \mathrm{sX}$ & 390T & 79.40 \\
$77 \mathrm{sx}$ & 390T & 94.41 \\
vea bm & 390T & 97.69 \\
vea bm & 390T & 97.38 \\
Psalb & 390T & 86.23 \\
Psalb & 390T & 77.97 \\
\hline
\end{tabular}

Abbreviations: 62 bc, canine sample, buffy coat; 77 sx, canine sample, conjunctival swab; vea bm, canine sample, bone marrow; psalb, human sample, blood from the MON-98 strains (considering that only me sequences were available for this MON) (Table 3). This could be in agreement with results reported by Haralambous et al. [24], which showed that some MON-1 and MON-98 zymodemes were not distinguished with a PCR-based typing method using the K26 antigen-coding gene as target sequence. Notably, the use of a real-time PCR-based assay with internal primers followed by HRM analysis allowed for the quick differentiation of sequences with the polymorphysm $390 \mathrm{~T}>\mathrm{G}$ not only in $L$. infantum isolates/strains, but also in clinical samples, enabling the potential application of this approach in population screening without parasite isolation and culturing.

Many marker sequences can be taken into consideration for genotyping purposes. The most suitable marker sequence depends on the level of resolution needed: highly variable markers can distinguish closely related genotypes but may not faithfully represent more distant relationships, while moderately variable markers will not 
be able to evidence the differences between closely related samples. The assay that we propose would not be able to distinguish closely related genotypes; therefore, it could be used to differentiate between relapse and re-infection only in cases where different 390T/G genotypes were found. However, it could be useful for epidemiological screening in regions where MLEE data are available, to rapidly identify zymodemes different from MON-1, 72 or 201 (e.g. for rapid screening of $L$. infantum genotypes in mammalian hosts). Once attributed a genotype (390T or 390G), other tests (e.g. MLEE or MLST) can be performed, depending on the level of resolution needed and on the classification system with which the results are to be compared.

Other zymodemes (i.e. MON-24, MON-78 and MON199) could be identified by exploiting the unique SNP found across the seven gene sequences. In particular MON-24, which is another common zymodeme [12, 38], could be differentiated by exploiting the polymorphisms $204 \mathrm{~T}>\mathrm{C}$ in the $i c d$ gene (Table 5) by using a HRM-based assay similar to the assay described here.

A possible limitation of this study is the unavailability of some zymodeme sequences in the database. Moreover, in many cases, only one strain with sequence information per zymodeme was available. This is important to keep in mind, since strains of the same zymodeme could present different genotypes (e.g. MON-29 in me, $i c d$ and $g 6 p d h$ genes) (Additional file 2: Table S1).

\section{Conclusions}

A total of 77 new sequences of seven genes encoding for metabolic enzymes in $L$. infantum isolates/strains have been produced and deposited in the GenBank database. The analysis of these sequences, together with sequences available in the database, allowed for the identification of genetic polymorphisms exploitable to differentiate the most common L. infantum zymodemes in the Mediterranean basin. In particular, a HRM-based assay aimed to differentiate the genotype 390T and 390G in the me gene was developed. The genotype $390 \mathrm{~T}$ correlated with zymodemes MON-1, 72, 201, allowing for the rapid identification of the majority of $L$. infantum genotypes. Once a parasite is attributed to genotype $390 \mathrm{~T}$ or $390 \mathrm{G}$, other tests (e.g. MLEE, MLST or MLMT) can be performed if more detailed information is needed. This assay has been successfully applied to clinical samples, demonstrating its potential applicability in investigating the role of other mammalian hosts in epidemiological screening.

\section{Additional files}

Additional file 1: Figure S1. Reference sequences and position of primers used in this study. a L. infantum strain MHOM/FR/1978/LEM75 cytosolic NADP-malic enzyme (me) gene, partial cds. (GenBank: DQ449701.1). Primers amplifying 5' region and 3' region are boxed and underlined, respectively. Internal primers are in bold. b L. infantum gene for phosphogluconate dehydrogenase (decarboxylating), strain MHOM/ FR/1978/LEM75 (GenBank: AM157139.1). c L. infantum strain MHOM/ FR/1978/LEM75 mitochondrial isocitrate dehydrogenase (icd) gene, complete cds (GenBank: DQ449672.1). d L. infantum gpi gene for glucose-6-phosphate isomerase, strain MHOM/FR/1978/LEM75 (GenBank: AJ620617.1). e L. infantum strain MHOM/FR/1978/LEM75 glucose-6-phosphate dehydrogenase (g6pdh) gene, complete cds (GenBank:DQ449770.1). f L. infantum strain MHOM/FR/1978/LEM75 mannose phosphate isomerase (mpi) gene, complete cds (GenBank: DQ449737.1). g L. infantum isolate MCAN/AR 10/MDP1 phosphoglucomutase gene, partial cds (GenBank: KJ643214.1). (DOCX $20 \mathrm{~kb}$ )

Additional file 2: Table S1. Summary of allelic profile and genotype of L. infantum zymodemes considered in this study. (DOCX $18 \mathrm{~kb}$ )

Additional file 3: Figure S2. Partial sequences of qPCR-MEint amplification products from reference strains and clinical isolates. Electropherograms encompassing polymorphic nucleotide at position 390 (arrows) are represented. (PDF $72 \mathrm{~kb}$ )

Additional file 4: Figure S3. Partial sequences of qPCR-MEint amplification products from clinical samples. Electropherograms encompassing polymorphic nucleotide at position 390 (arrows) are represented. (PDF $570 \mathrm{~kb}$ )

\section{Abbreviations}

qPCR: Quantitative real-time PCR; VL: Visceral leishmaniasis; CL: Cutaneous leishmaniasis; HRM: High-resolution melting; MLEE: Multilocus enzyme electrophoresis; MLST: Multilocus sequence typing; MLMT: Multilocus microsatellite typing

\section{Acknowledgements}

We thank Dr Federica Bruno and Dr Germano Castelli from IZS Palermo for providing Leishmania spp. DNA. We thank Dr Emanule Gasparini and Dr Barbara Bianchi from the Santa Teresa Veterinary Clinic, Fano (PU) Italy, for providing canine clinical samples. We also thank Dr Benedetta Canovari and Professor Francesco Barchiesi from Ospedali Riuniti Marche Nord for providing a blood sample from a human VL patient, and Dr Elizabeth Tremmel for English revision.

\section{Funding}

This work was partially supported by the Italian Ministry of Health (grant number Ricerca corrente 2013 IZS SI 3/14 RC). The funder had no role in study design, data collection and analysis, interpretation of the data, or writing the manuscript.

\section{Availability of data and materials}

All data generated or analysed during this study are included in this published article and its Additional files.

\section{Authors' contributions}

Conception and design of the study: MC and LG. Acquisition of data: MC, AD and FA. Analysis and interpretation of data: MC, LG, FV and MM. Drafting the article: $M C$ and LG. Revising the article critically for important intellectual content: AD, FA, FV and MM. All authors read and approved the final manuscript.

\section{Ethics approval}

Approval of the study was obtained on 31st July 2012 from the Ethical Committee for Animal Experiments of the University of Urbino (CESA) [study title "Diagnosi biomolecolare della leishmaniosi attraverso l'uso di campioni clinici non invasivi e loro utilizzo per il monitoraggio terapeutico" (Prot. CESA 2/2012)].

\section{Consent for publication}

Not applicable.

Competing interests

The authors declare that they have no competing interests. 


\section{Publisher's Note}

Springer Nature remains neutral with regard to jurisdictional claims in published maps and institutional affiliations.

\section{Author details}

'Department of Biomolecular Sciences, University of Urbino "Carlo Bo", Urbino, PU, Italy. ${ }^{2}$ Istituto Zooprofilattico Sperimentale of Sicily "A Mirri", Palermo, PA, Italy.

Received: 14 July 2018 Accepted: 10 October 2018

Published online: 01 November 2018

\section{References}

1. Akhoundi M, Kuhls K, Cannet A, Votýpka J, Marty P, Delaunay P, et al. A historical overview of the classification, evolution, and dispersion of Leishmania parasites and sandflies. PLoS Negl Trop Dis. 2016;10:e0004349.

2. Kostygov AY, Yurchenko V. Revised classification of the subfamily Leishmaniinae (Trypanosomatidae). Folia Parasitol (Praha). 2017;64:020.

3. Alvar J, Vélez ID, Bern C, Herrero M, Desjeux P, Cano J, et al. Leishmaniasis worldwide and global estimates of its incidence. PLoS One. 2012;7:e35671.

4. World Health Organization. Control of the leishmaniases. World Health Organ Tech Rep Ser. 2010;949:xii-xiii 1-186.

5. Rioux JA, Lanotte G, Serres E, Pratlong F, Bastien P, Perieres J. Taxonomy of Leishmania. Use of isoenzymes. Suggestions for a new classification. Ann Parasitol Hum Comp. 1990;65:111-25.

6. Aït-Oudhia K, Harrat Z, Benikhlef R, Dedet JP, Pratlong F. Canine Leishmania infantum enzymatic polymorphism: a review including 1023 strains of the Mediterranean area, with special reference to Algeria. Acta Trop. 2011; 118:80-6.

7. Millán J, Ferroglio E, Solano-Gallego L. Role of wildlife in the epidemiology of Leishmania infantum infection in Europe. Parasitol Res. 2014;113:2005-14.

8. Pratlong F, Lami P, Ravel C, Balard Y, Dereure J, Serres G, et al. Geographical distribution and epidemiological features of Old World Leishmania infantum and Leishmania donovani foci, based on the isoenzyme analysis of 2277 strains. Parasitology. 2013;140:423-34.

9. Kuhls K, Alam MZ, Cupolillo E, Ferreira GEM, Mauricio IL, Oddone R, et al. Comparative microsatellite typing of New World Leishmania infantum reveals low heterogeneity among populations and its recent Old World origin. PLoS Negl Trop Dis. 2011;5:e1155.

10. Pratlong F, Rioux J-A, Marty P, Faraut-Gambarelli F, Dereure J, Lanotte G, et al. Isoenzymatic analysis of 712 strains of Leishmania infantum in the south of France and relationship of enzymatic polymorphism to clinical and epidemiological features. J Clin Microbiol. 2004;42:4077-82.

11. Campino L, Pratlong F, Abranches P, Rioux J-A, Santos-Gomes G, Alves-Pires $C$, et al. Leishmaniasis in Portugal: enzyme polymorphism of Leishmania infantum based on the identification of 213 strains. Trop Med Int Heal. 2006; 11:1708-14.

12. Chicharro C, Jiménez Ml, Alvar J. Iso-enzymatic variability of Leishmania infantum in Spain. Ann Trop Med Parasitol. 2003;97(Suppl. 1):57-64.

13. Martin-Sanchez J, Gramiccia M, Di Muccio T, Ludovisi A, Morillas-Márquez F. Isoenzymatic polymorphism of Leishmania infantum in southern Spain. Trans R Soc Trop Med Hyg. 2004;98:228-32.

14. Alvar J, Cañavate C, Gutiérrez-Solar B, Jiménez M, Laguna F, López-Vélez R, et al. Leishmania and human immunodeficiency virus coinfection: the first 10 years. Clin Microbiol Rev. 1997;10:298-319.

15. Gramiccia M, Scalone A, Di Muccio T, Orsini S, Fiorentino E, Gradoni L. The burden of visceral leishmaniasis in Italy from 1982 to 2012: a retrospective analysis of the multi-annual epidemic that occurred from 1989 to 2009. Euro Surveill. 2013;18:20535.

16. Botilde Y, Laurent T, Quispe Tintaya W, Chicharro C, Cañavate C, Cruz I, et al. Comparison of molecular markers for strain typing of Leishmania infantum. Infect Genet Evol. 2006;6:440-6.

17. Cortes S, Maurício IL, Kuhls K, Nunes M, Lopes C, Marcos M, et al. Genetic diversity evaluation on Portuguese Leishmania infantum strains by multilocus microsatellite typing. Infect Genet Evol. 2014;26:20-31.

18. Mauricio IL, Yeo M, Baghaei M, Doto D, Pratlong F, Zemanova E, et al. Towards multilocus sequence typing of the Leishmania donovani complex: resolving genotypes and haplotypes for five polymorphic metabolic enzymes (ASAT, GPI, NH1, NH2, PGD). Int J Parasitol. 2006;36:757-69.

19. Zemanová E, Jirků M, Mauricio IL, Horák A, Miles MA, Lukeš J. The Leishmania donovani complex: genotypes of five metabolic enzymes (ICD,
ME, MPI, G6PDH, and FH), new targets for multilocus sequence typing. Int J Parasitol. 2007;37:149-60.

20. El Baidouri F, Diancourt L, Berry V, Chevenet F, Pratlong F, Marty P, et al. Genetic structure and evolution of the Leishmania genus in Africa and Eurasia: what does MLSA tell us. PLoS Negl Trop Dis. 2013;7:e2255.

21. Schonian G, Kuhls K, Mauricio IL. Molecular approaches for a better understanding of the epidemiology and population genetics of Leishmania. Parasitology. 2011;138:405-25.

22. Herrera G, Hernández C, Ayala MS, Flórez C, Teherán AA, Ramírez JD. Evaluation of a Multilocus Sequence Typing (MLST) scheme for Leishmania (Viannia) braziliensis and Leishmania (Viannia) panamensis in Colombia. Parasit Vectors. 2017;10:236.

23. Chicharro C, Llanes-Acevedo P, García E, Nieto J, Moreno J, Cruz I. Molecular typing of Leishmania infantum isolates from a leishmaniasis outbreak in Madrid, Spain, 2009 to 2012. Euro Surveill. 2013:18:20545.

24. Haralambous C, Antoniou M, Pratlong F, Dedet J-PP, Soteriadou K. Development of a molecular assay specific for the Leishmania donovani complex that discriminates $L$. donovani/Leishmania infantum zymodemes: a useful tool for typing MON-1. Diagn Microbiol Infect Dis. 2008;60:33-42.

25. Ye J, Coulouris G, Zaretskaya I, Cutcutache I, Rozen S, Madden TL. PrimerBLAST: a tool to design target-specific primers for polymerase chain reaction. BMC Bioinformatics. 2012;13:134

26. Hall TA. BioEdit: a user-friendly biological sequence alignment editor and analysis program for Windows 95/98/NT. Nucleic Acids Symp Ser. 1999; 41:95-8.

27. Guindon S, Dufayard J-F, Lefort V, Anisimova M, Hordijk W, Gascuel O. New algorithms and methods to estimate maximum-likelihood phylogenies: assessing the performance of PhyML 3.0. Syst Biol. 2010;59:307-21.

28. Lefort V, Longueville J-E, Gascuel O. SMS: Smart Model Selection in PhyML. Mol Biol Evol. 2017;34:2422-4.

29. Letunic I, Bork P. Interactive tree of life (iTOL) v3: an online tool for the display and annotation of phylogenetic and other trees. Nucleic Acids Res. 2016:44:W242-5.

30. Ceccarelli M, Galluzzi L, Migliazzo A, Magnani M. Detection and characterization of Leishmania (Leishmania) and Leishmania (Viannia) by SYBR green-based real-time PCR and high resolution melt analysis targeting kinetoplast minicircle DNA. PLoS One. 2014;9:e88845.

31. Ceccarelli M, Galluzzi L, Diotallevi A, Gasparini E, Migliazzo A, Magnani M. The relevance of molecular diagnosis in a dog vaccinated against leishmaniasis. Vet Med Anim Sci. 2016;4:4

32. Galluzzi L, Diotallevi A, De Santi M, Ceccarelli M, Vitale F, Brandi G, et al. Leishmania infantum induces mild unfolded protein response in infected macrophages. PLoS One. 2016;11:e0168339.

33. Ceccarelli M, Galluzzi L, Sisti D, Bianchi B, Magnani M. Application of qPCR in conjunctival swab samples for the evaluation of canine leishmaniasis in borderline cases or disease relapse and correlation with clinical parameters. Parasit Vectors. 2014;7:460.

34. Miró G, Müller A, Montoya A, Checa R, Marino V, Marino E, et al. Epidemiological role of dogs since the human leishmaniosis outbreak in Madrid. Parasit Vectors. 2017;10:209.

35. Oleaga A, Zanet S, Espí A, Pegoraro de Macedo MR, Gortázar C, Ferroglio E. Leishmania in wolves in northern Spain: a spreading zoonosis evidenced by wildlife sanitary surveillance. Vet Parasitol. 2018;255:26-31.

36. Gramiccia M. The identification and variability of the parasites causing leishmaniasis in HIV-positive patients in Italy. Ann Trop Med Parasitol. 2003; 97(Suppl. 1):65-73.

37. Pennisi M-G, Cardoso L, Baneth G, Bourdeau P, Koutinas A, Miró G, et al. LeishVet update and recommendations on feline leishmaniosis. Parasit Vectors. 2015:8:302.

38. Haralambous C, Dakkak A, Pratlong F, Dedet J-P, Soteriadou K. First detection and genetic typing of Leishmania infantum MON-24 in a dog from the Moroccan Mediterranean coast: genetic diversity of MON-24. Acta Trop. 2007;103:69-79. 